\title{
O Papel Dos Métodos Adequados De Solução De Conflitos Em Tempos De Pandemia Da Covid-19 No Âmbito Do Poder Judiciário De Alagoas
}

\author{
Adrualdo de Lima Catão *
}

Universidade Federal de Alagoas, Programa de Pós-Graduação em Direito, Maceió-AL, Brasil. (i) https://orcid.org/oooo-0003-3419-124X

Carlos David Franca Santos**

Universidade Federal de Alagoas, Programa de Pós-Graduação em Direito, Maceió-AL, Brasil. (iD) https://orcid.org/0000-0002-7813-9788

Mylla Gabriely Araújo Bispo ***

Universidade Federal de Alagoas, Programa de Pós-Graduação em Direito, Maceió-AL, Brasil

Resumo: Os Métodos Adequados de Solução de Conflitos (MASCs) se caracterizam pela pacificação de lides, sem que se recorra ao processo tradicional. Desempenhando, assim, um papel de vital importância no âmbito do Poder Judiciário. Diante da pandemia da COVID-19, o Conselho Nacional de Justiça, por meio da Resolução $n^{0} 313 / 2020$, regulamentou o funcionamento do Judiciário por meio do teletrabalho, aplicando-se tal normativa também às audiências de mediação e conciliação. Nesse sentido, o presente trabalho visa analisar se o Poder Judiciário de Alagoas, em Maceió, implementou essa resolução em consonância com os contornos do acesso à justiça, do início da pandemia até o mês de julho de 2020, no que tange aos MASCs. Para tal, utilizou-se da pesquisa bibliográfica, da pesquisa empírica- por meio do mapeamento do número de audiências de mediação e conciliação realizadas na esfera do Judiciário de Alagoas, em Maceió, de março a julho de 2020. Utilizou-se da análise quantitativa, por meio da estatística descritiva, na modalidade frequência absoluta. Os resultados mostram que a posição do Judiciário de Alagoas, em Maceió, foi em conformidade com os ditames do acesso à justiça, de acordo com os parâmetros acima, haja vista o número expressivo de audiências autocompositivas no período mencionado.

Palavras-chave: Métodos adequados de solução de conflitos (MASCs). Pandemia. Poder Judiciário. Tecnologias. Poder Judiciário de Alagoas.

\footnotetext{
* Doutor em Direito pela Universidade Federal de Pernambuco. Professor da Universidade Federal de Alagoas. Líder do grupo de pesquisa "Pragmatismo Jurídico, Teorias da Justiça e Direitos Humanos". Email: adrualdocatao@gmail.com

** Mestrando em Direito Público da Universidade Federal de Alagoas. Bolsista do Programa de Apoio à Pós-Graduação (PROAP/ CAPES). E-mail: carlosdavid94@gmail.com

**** Mestranda em Direito Público da Universidade Federal de Alagoas. E-mail: mylla.bispo@ @hotmail.com
}

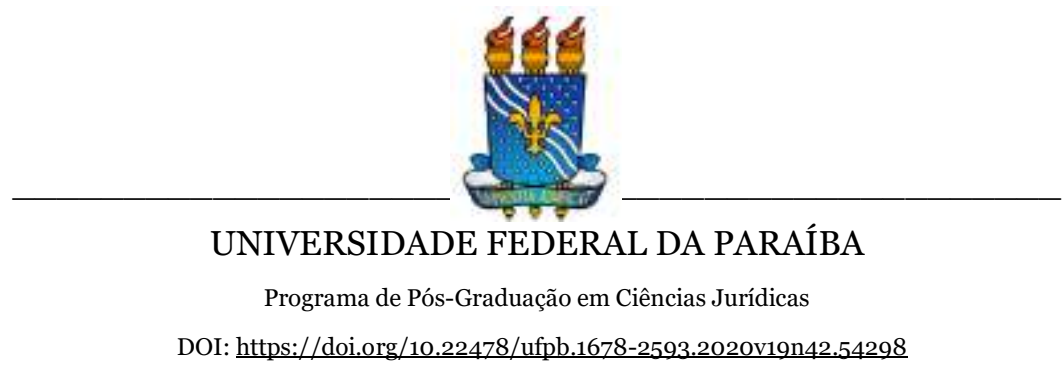




\title{
O Papel Dos Métodos Adequados De Solução De Conflitos Em Tempos De Pandemia Da Covid-19 No Âmbito Do Poder Judiciário De Alagoas
}

\author{
Adrualdo de Lima Catão
}

Carlos David Franca Santos ${ }^{1}$

Mylla Gabriely Araújo Bispo

\section{INTRODUÇÃO}

Os conflitos são inerentes à condição humana. Não havendo de se falar, portanto, em evitá-los, mas em tratá-los da maneira mais apropriada. Nessa linha, os métodos adequados de solução de conflitos (MASCs) se mostram uma via distinta da do processo judicial tradicional. Assim, a depender do litígio em questão, podem ser mais profícuos às partes, haja vista os princípios ínsitos a esses mecanismos, os quais impulsionam uma solução construída pelas partes, ao invés de uma imposição judicial.

Dentre os MASCs, os que se destacam no âmbito do Código de Processo Civil de 2015 são a mediação, a conciliação e a arbitragem, sendo os dois primeiros o enfoque deste trabalho. Tais instrumentos, por sua vez, têm em comum a existência de um terceiro imparcial que propulsiona o diálogo entre as partes. O traço distintivo entre eles é que na mediação o terceiro imparcial não pode apresentar sugestões de soluções do conflito às partes, já na conciliação pode. Outrossim, a

${ }^{1} \mathrm{O}$ presente trabalho foi realizado com apoio da Coordenação de Aperfeiçoamento de Pessoal de Nível Superior - Brasil (CAPES) - Código de Financiamento o01. 
mediação se mostra mais adequada diante de conflitos mais profundos e dotados de uma maior carga emocional, ao passo que a conciliação é mais conveniente em face de conflitos mais superficiais.

O manejo dos instrumentos retro mencionados vem sendo fomentado pelo Conselho Nacional de Justiça, inclusive diante do contexto atual marcado pela pandemia da COVID-19. Nesse cenário, foi expedida a Resolução $n^{0}$ 313/2020 que disciplina e padroniza as atividades do Judiciário Brasileiro durante a pandemia. Trata-se de regramento que visa evitar o contágio da doença, ao mesmo tempo em que objetiva a garantia do acesso à justiça nesse período, por meio do teletrabalho. Esse modo de funcionamento por parte do Judiciário abarcou, igualmente, as audiências de mediação e conciliação, com a necessidade respeito aos princípios atinentes a tais instrumentos, quando da sua realização no ambiente virtual.

Em conformidade com essa diretriz, o Tribunal de Justiça do Estado de Alagoas, por meio do Ato Normativo $\mathrm{n}^{0} 11$ estabelece a realização de audiências processuais por meio de videoconferências, assim como a prática de audiências de mediação e conciliação no ambiente virtual. Dessa forma, à luz dos dados fornecidos pelo Setor de Divisão de Estatísticas do Tribunal de Justiça de Alagoas DETJ/AL, de março (quando tal norma foi editada) até o mês de julho de 2020, verifica-se a realização de audiências online de natureza autocompositiva. Este trabalho possui, portanto, o objetivo de analisar se o Poder Judiciário de Alagoas, em Maceió, adotou um posicionamento em consonância com os contornos do acesso à justiça desde o início da pandemia até o momento atual, no que tange os MASCs.

O método utilizou da pesquisa bibliográfica, a fim de compreender os MASCs e o posicionamento do Judiciário diante da pandemia. Em seguida, fez-se uma pesquisa empírica, por meio do mapeamento do número de audiências de mediação e conciliação realizadas na esfera do Judiciário de Alagoas, em Maceió, de março a julho de 2020. Adotou-se a análise quantitativa, por meio da estatística descritiva, na modalidade frequência absoluta. A hipótese 
O Papel Dos Métodos Adequados De Solução De Conflitos Em Tempos De...

de trabalho é que o Poder Judiciário ao implementar a Resolução $\mathrm{n}^{0}$ 313/2020 do CNJ atuou em consonância com os parâmetros do acesso à justiça. Os resultados mostram que a posição do Judiciário de Alagoas, foi em conformidade com os contornos do acesso à justiça, de acordo com os critérios acima, haja vista o número expressivo de audiências autocompositivas no período mencionado.

\section{BREVES CONSIDERAÇÕES ACERCA DA IDEIA DO CONFLITO}

A priori, ao se referir à palavra conflito, tem-se a ideia de algo negativo, que acarreta em prejuízos, para ao menos uma das partes envolvidas. A moderna teoria do conflito vem, no entanto, compreendendo-o como algo positivo, natural na relação entre os seres vivos e que pode ser encarado de maneira otimista (AZEVEDO, 2016, p. 49-51).

A psicologia, por sua vez, encara o conflito como parte das relações humanas, tanto numa concepção espacial, quanto relacional. São, pois, necessários para o desenvolvimento e a ampliação de qualquer sistema social, sob pena de este quedar-se paralisado. A maneira como se lida com esses enfrentamentos é que podem acarretar em determinadas ações e reações, mas não se pode considerá-los necessariamente negativos (ZAPPAROLLI; KRÄHENBÜHL, 2012, p. 21).

Enquanto fatos da vida a serem gerenciados, os conflitos não devem ser considerados patologias que resultam em agressão e que, portanto, devem ser prevenidas. Na realidade, o mais adequado é ter em mente a prevenção não do conflito, mas de situações que alimentem disputas, discórdias, violências e crimes. Devendo haver, pois, uma administração devida dos aspectos envolvidos em cada caso (ZAPPAROLLI; KRÄHENBÜHL, 2012, p. 21). 
Os conflitos são, desse modo, integrantes contínuos das relações humanas. Podem eles orbitarem ao redor da escassez de bens, da inexorabilidade de obrigações, das diferenças. O fato é que são provenientes da frustração dos interesses de um dos sujeitos envolvidos na querela. Há, em consequência, a produção de emoçõessentimentos e desejos- os quais podem se converter em raiva, e esta pode culminar em atitudes destrutivas- hostilidade, violências e até em doenças (ZAPPAROLLI; KRÄHENBÜHL, 2012, p. 21).

Mais ainda atualmente, faz-se mister o gerenciamento adequado dos conflitos, devido a determinadas circunstâncias, conforme exposto por Paulo Eduardo Alves da Silva (2019, p.2):

A ocorrência de disputas de interesses na sociedade civil, entre indivíduos, grupos, ou com o Estado, é inevitável. Por conta da configuração social contemporânea, esses conflitos tornam-se mais frequentes e mais complexos. Os dados sobre o volume e a movimentação processual da Justiça brasileira, em progressivo aumento nos últimos anos, são um indicativo claro da tendência de aumento da mobilização por direitos. Relatórios similares de outros países sinalizam no mesmo sentido.

Com o advento dos Estados Modernos, cristalizou-se a concepção de que o Estado seria o único apto a proceder à resolução dos conflitos. Isso se daria por meio da jurisdição e do processo judicial, pautados num procedimento de investigação racional da verdade baseado no debate entre os litigantes. Podendo o julgador, nessa linha, formar o seu livre convencimento, desde que balizado por racionalidade e motivação. Há, no entanto, questionamentos em voga desde as últimas décadas. Tais indagações consistem em problematizar se o método estatal tradicional é o mais adequado para produzir justiça, se poderia a própria sociedade realizar a pacificação de disputas de interesses mais justas do que as promovidas pelo Estado, e quais outros mecanismos seriam aptos a pacificar os conflitos (DA SILVA, 2019, p. 2). 
O Papel Dos Métodos Adequados De Solução De Conflitos Em Tempos De...

\section{OS MÉTOdOS ADEQUAdOS DE SOLUÇÃo DE CONFLITOS (MASCS) NO ROL DAS VIAS PRINCIPAIS DE PACIFICAÇÃO DE CONFLITOS}

Inicialmente referidos no plano nacional como meios alternativos de solução de conflitos, a expressão MASCs é oriunda da língua inglesa "alternative dispute resolutions" e diz respeito a uma solução diferente da provida por um processo judicial. Tais formas de resolução concernem a uma série de instrumentos de solução de conflitos - a mediação, a conciliação, a arbitragem, a negociação (DA SILVA, 2019, p. 5).

A tradução literal para o idioma português, "alternativas", não se mostrou satisfatória no contexto brasileiro. Isso porque, a ideia ínsita a esse vocábulo implica na existência de um meio principal, qual seja- a resolução provida pelo Poder Judiciário, por meio do processo tradicional, e consequentemente a mediação, a conciliação, a arbitragem, a negociação seriam meios secundários. Inferiores, pois, ao provimento jurisdicional clássico. Assim, tal termo tornou-se carregado de uma conotação negativa (MAZZEI; CHAGAS, 2018, p. 329).

Ante tal problemática, pensou-se na utilização dos termos extrajudiciais e consensuais. O primeiro se mostrou insuficiente, haja vista o fato de o Código de Processo Civil de 2015 estabelecer a realização de sessões de mediação e de conciliação no decorrer do processo judicial, além da previsão no mesmo diploma de requisitos para credenciamento de conciliadores e mediadores judiciais. O CNJ, a seu turno, para arrematar a questão estabelece, em sua Resolução $\mathrm{n}^{0}$ 125, o uso da mediação e da conciliação como políticas judiciárias. Demonstrada, portanto, a insuficiência do termo devido ao fato de poderem tais mecanismos se darem tanto no âmbito judicial, quanto fora dele (MAZZEI; CHAGAS, 2018, p. 329-330). 
Já o segundo não se mostra a contento, uma vez que acaba por excluir o instrumento da arbitragem, pois, em que pese serem a mediação e a conciliação pautadas na concepção de consensualidade, o mesmo não se aplica à arbitragem. Esta é caracterizada pela participação de um terceiro que decide a causa de maneira definitiva e adjudicada. Não se trata, portanto, de uma decisão prolatada pelo Estado Juiz, nem permeada por um consenso. Assim, não convém o uso da palavra "consensual" para se referir a todos os instrumentos que não sejam o do processo judicial tradicional (MAZZEI; CHAGAS, 2018, p. 331).

A expressão "adequados" parece, então, ser a mais apropriada. Outro ponto problemático, todavia, é o atinente ao uso das palavras "solução" ou "resolução" de conflitos. Cabível registrar que o fim dos conflitos não é algo almejado pelo direito. Este visa, na verdade, retirar algo de positivo das contendas. O ponto não é resolver ou solucionar as lides no sentido de erradicá-las. Sendo assim, a expressão "tratamento adequado de conflitos" é a mais devida, visto que, dessa maneira, está-se a reconhecer as diferenças entre cada mecanismo. Sendo que cada instrumento é o mais acertado para pacificar determinado tipo de conflito. Existindo, no entanto, a possibilidade de conjugação entre esses métodos (MAZZEI; CHAGAS, 2018, p. 332336).

Ante uma conjuntura na qual uma sentença demora, em média, 1 ano e 4 meses a ser prolatada- na fase de conhecimento; 4 anos e 6 meses - na fase de execução, e do recebimento de 103.650 mil novos processos pelo Supremo Tribunal Federal, mostra-se imperioso pensar em soluções outras. Assim, os mecanismos adequados de resolução de conflitos devem ser fomentados. Sem se retirar, contudo, o papel crucial exercido pelo Poder Judiciário na garantia da pacificação social. Só que não deve ser o método adversarial tradicional o único ou o principal meio de pacificação dos litígios (TOFFOLI, 2019, p. 18-19). 
Merece guarida, desse modo, a tese esposada por José Ricardo Suter e Rozane da Rosa Cachapuz (2016, p. 64) acerca dos métodos adequados de solução de conflitos abaixo exposta:

Os meios consensuais de resolução de conflitos são alternativas para solucionar problemas entre as pessoas. Amparam a construção de uma sociedade mais estruturada, à medida que envolve as partes litigantes na resolução de seus litígios sem a intervenção do Estadojuiz. Desta maneira os meios consensuais de resolução de conflitos como a mediação e a conciliação apontam para um novo desafio ao Poder Judiciário Brasileiro, pois ainda não há preparo adequado para praticá-los, tanto de ordem física, quanto social e econômica.

Interessante a classificação exposta por Diogo Assumpção Rezende de Almeida (2014, p. 2), que, a princípio, divide os meios de solução de conflitos em- autocompositivos, impositivos e mistos.

O primeiro bloco engloba a mediação, a conciliação e a negociação. Esta última se distingue dos da mediação e da conciliação pelo fato de não haver um terceiro no procedimento. Há, pois, uma forma direta de comunicação entre os participantes, sendo incumbência deles próprios a procura de uma resolução do conflito sem a participação de um agente externo à relação (DE ALMEIDA, 2014, p. 2). Enquanto isso, o segundo grupo, também conhecido como métodos adversariais, justamente pelo fato de as partes assumirem posições de adversários do procedimento.

Almejam, essas partes, convencer o terceiro que decidirá com base nos fundamentos por eles trazidos. Nesse sentido, pelo fato de a decisão ser dada pelo terceiro, não há de se falar em protagonismo da decisão pelas partes. Tais métodos abarcam tanto a jurisdição, quanto a arbitragem. A distinção entre elas se dá, pois no caso da primeira o seu exercício é realizado pelo Estado Juiz, com respeito a princípios como a publicidade e o duplo grau de jurisdição. Caracterizando-se, também, como um procedimento rígido. Por outro lado, a arbitragem é um instrumento mais flexível e o terceiro que efetua a decisão é um profissional escolhido pelas partes. Há, igualmente, uma preocupação 
maior com a celeridade do procedimento na arbitragem ao seu comparar com o exercício da jurisdição (DE ALMEIDA, 2014, p. 3).

A presença de um terceiro imparcial devidamente capacitado para utilizar as técnicas adequadas com o fim de estimular - a escuta ativa, a reformulação de situações, a cooperação, o ganha-ganha, além de técnicas outras- é um aspecto em comum entre a mediação e os demais mecanismos consensuais de solução de conflitos. Observadas, claro, as nuances de cada método, esse ponto congruente também consiste na necessidade de esse terceiro ser criativo, de fomentar a criatividade e uma visão sistemática voltada para a resolução dos impasses (SALES; DE ANDRADE, 2017, p. 218).

Os instrumentos mistos, a seu turno, são pautados pela divisão em etapas. Assim, a primeira fase se utiliza de um determinado instrumento de solução de conflitos, e caso tal mecanismo reste frustrado, resta prevista a utilização de outro mecanismo já previamente estabelecido. Isso se dá, a título de exemplo- na mediação arbitragem, na arbitragem-mediação, na dispute boards, no minijulgamento (DE ALMEIDA. 2014, p. 3).

Dar-se-á ênfase, neste trabalho, aos métodos adequados de solução de conflitos, então considerados os instrumentos autocompositivos, em especial à mediação e à conciliação.

\subsection{Mediação: primazia da autonomia das partes}

Inicialmente, a regulação da mediação por meio de lei obteve oposição considerável, o que resultou no seu não estabelecimento por essa via (ao menos no princípio). Ante tal conjuntura, os defensores do instrumento em questão tentaram realizar o seu regramento no âmbito do Poder Judiciário, e aos poucos lograram êxito nessa meta. Desse modo, a Resolução $\mathrm{n}^{0} 125$ do Conselho Nacional de Justiça foi um ponto de referência no que tange ao avanço dos métodos consensuais de conflitos, aí incluídas a mediação e a conciliação (DA SILVA, 2019, p. 10-11). 
Nessa toada, em 2014 foi aprovada a Lei $n^{0} 13.140 / 15$, a chamada Lei de Mediação, a qual regula a mediação entre particulares. No mesmo ano, o projeto do Novo Código de Processo Civil trazia consigo a ideia de regular o mecanismo em comento. Projeto esse que vingou e culminou na aprovação do Código de Processo Civil de 2015, o qual traz em seu bojo, no capítulo de suas normas fundamentais, a mediação, a conciliação e a arbitragem como ressalvas à garantia da inafastabilidade da jurisdição (DA SILVA, 2019, p. 11).

Nesse norte, lúcidas são as ponderações feitas por Lília Maia de Morais Sales e Luana Silveira de Andrade (2017, p. 217) acerca dos regramentos que foram recentemente estabelecidos acerca da mediação:

Percebe-se que a legislação traz um novo paradigma para a solução de conflitos no país, visto que a mediação, tratada como meio consensual de resolução de litígios, passa a ser estimulada e não mais considerada como mero meio alternativo de solução de divergências.

A legislação brasileira ressalta a importância da mediação de conflitos e com isso estimula e fortalece todos os mecanismos consensuais com a negociação, conciliação e arbitragem, apresentando um novo paradigma para a formação do profissional do Direito e consequentemente, desenvolvimento de habilidades novas a adequadas a esse novo paradigma.

Em relação aos mediadores e aos conciliadores, foi atribuída a observância de princípios gerais, assim como o respeito às regras de confidencialidade, a certificação de capacitação, à quarentena, etc. Igualmente, a Lei $\mathrm{n}^{0}$ 13.105/15 ratificou as disposições da referida Resolução $\mathrm{n}^{\mathrm{o}} 125$ do $\mathrm{CNJ}$, no sentido de promover a institucionalização dos centros judiciários de solução de conflito. Previsões essas voltadas para a articulação de tentativas de conciliações prévias ao processo judicial e também já no âmbito do processo judicial (DA SILVA, 2019, p. 11-12).

Segundo Lília Maia de Morais Sales (2016, p. 967):

A mediação é mecanismo de solução de conflitos que tem como premissa o diálogo inclusivo e cooperativo entre as pessoas e a participação de um terceiro imparcial - o mediador - que, com a capacitação adequada, facilita a comunicação entre as partes sem propor ou sugerir, possibilitando a construção de uma solução satisfatória 
pelas próprias partes. A mediação possibilita, por meio de técnicas próprias utilizadas pelo mediador, a identificação do conflito real vivenciado e a sua solução. A mediação requer a discussão sobre as posições, interesses e valores envolvidos e, a partir da ressignificação desses valores, permite a construção participativa do consenso.

Possível, também, definir a mediação, conforme defendem alguns autores, como um processo autocompositivo, no qual as partes envolvidas são assistidas por um terceiro imparcial, sem interesse na causa, a fim de que se logre a composição. Esta é formada por uma série de atos procedimentais que resulta na habilitação das pessoas envolvidas no conflito, a fim de que seja encontrada uma solução que atenda aos interesses de todas as partes envolvidas. Sendo, destarte, a participação do terceiro neutro crucial para se atingir esse desiderato, sem, contudo, implicar na perda da autonomia das partes na resolução da disputa. A mediação é, então, uma espécie de negociação facilitada (AZEVEDO, 2016, p. 20).

Uma marca característica da mediação é a informalidade. Esta, por sua vez, desemboca na oralidade, a qual se mostra de grande valia, visto que o instrumento em comento visa, em última análise, restaurar as relações entre as partes. Valendo-se para tal, do debate e do consenso ao tratar dos conflitos de interesses. Esse assentimento, por sua vez, tem como pressuposto a autonomia das decisões das partes. Prescindindo, pois, de homologação judicial futura. Ainda assim, caso ao final se chegue à uma decisão imoral ou injusta, é porque o procedimento foi falho. Fazendo-se mister, desse modo, a orientação do desenvolvimento da mediação. Não se configurando, no entanto, esse tipo de aconselhamento como sugestão de solução para o litígio (SPENGLER, 2010, p. 46).

Apropriado, sobretudo, diante de conflitos nos quais haja envolvimento emocional, a mediação mostra-se exemplar nas seguintes searas: direito de família, direito trabalhista, direito cível. Aspecto interessante é que em vista da adequação desse instrumento nos casos em que haja uma carga emocional envolvida, podendo tais relações se referirem ao passado, ao presente, ou até desembocarem 
no futuro, é possível por meio dele criar ou recriar vínculos (SIQUEIRA; PAIVA, 2016, p. 184).

Em oposição ao conteúdo da decisão judicial, a qual é carregada de uma linguagem fria em terceira pessoa e determinada por lei, a mediação almeja a aproximação entre as partes. Isso porque, por meio da análise do conflito, há o desfazimento da circunstância de polos antagônicos conflitantes, e em consequência do litígio em si. O instituto em questão tem o escopo de aportar os envolvidos à uma perspectiva pautada mormente na racionalidade e, assim, obter algo positivo no plano interior dos indivíduos, como saldo do conflito (SPENGLER, 2010, p. 41-42).

Aspectos que devem ser respeitados no âmbito da mediação são, dentre outros, a possibilidade da comunicação entre as partes, a opção de uma análise mais profunda sobre o que está por detrás do conflito. Afora a prerrogativa que assiste aos envolvidos no processo mediativo de não participar dele, ou de encerrar a qualquer momento as negociações, é dispensável a obtenção de um acordo. Diferentemente, pois, de um processo vinculante, no qual a não participação ou a desistência podem resultar numa perda processual ou material (AZEVEDO, 2016, p. 20-21).

Noutro giro, quando se está a tratar dos procedimentos não vinculantes, não se verifica a ocorrência de maiores prejuízos em razão da ausência no processo. Não há, portanto, ônus de participar do referido procedimento. Assim, a mediação e a conciliação são métodos não vinculantes. Cabendo o seu direcionamento e o seu controle a um terceiro, mas com a manutenção dos resultados pelas partes (AZEVEDO, 2016, p. 21).

Pautada na ideia de continuidade das relações futuras, com base na prevenção de eventuais controvérsias, a mediação possui como pilares a liberdade de escolha e a consensualidade. Trata-se de mecanismo que se preocupa com a celeridade, mas não apenas com esse ponto, haja vista o protagonismo às partes que é primado por esse instrumento, com o fim de se atingir eficiência e validade judicial, seja 
o conflito judicial ou extrajudicial. Sendo, pois, a alternativa mais destacada na garantia da celeridade e da efetividade. Proporcionando, por conseguinte, em um contributo ao estabelecimento de uma cultura de paz social (CARNEIRO, 2019, p. 14-15).

\title{
3.2 Conciliação: objetividade e celeridade no tratamento de conflitos
}

Instrumento que conta com o diálogo das partes envolvidas, a conciliação é um meio autocompositivo de pacificação de conflitos que possui a participação de um terceiro capacitado e imparcial que pode recomendar soluções àquelas. O instituto em questão pode se dar tanto na esfera judicial, quanto extrajudicial. O seu uso tem se dado de forma vasta no processo civil- mormente na seara de família, no âmbito da Justiça Trabalhista e nos Juizados Especiais. Da conciliação pode emergir um acordo livre, responsável e, dessa forma, com maior possibilidade de cumprimento (SALES, 2014, p. 261).

Nessa mesma linha conceitua o Manual de Mediação Judicial (2016, p. 21):

\begin{abstract}
A conciliação pode ser definida como um processo autocompositivo breve no qual as partes ou os interessados são auxiliados por um terceiro, neutro ao conflito, ou por um painel de pessoas sem interesse na causa, para assisti-las, por meio de técnicas adequadas, a chegar a uma solução ou a um acordo [...]
\end{abstract}

Nesse procedimento, as partes são responsáveis pelo encontro da solução para os seus problemas. Há, desse modo, a fixação de responsabilidade no que tange a assunção de compromissos. Podendo as relações serem, inclusive, aprimoradas desse momento em diante. Perspectiva distinta, portanto, de uma decisão judicial, a qual implicará em vencedores e vencidos. A conciliação, por outro lado, rompe com esse paradigma, afora a questão da diminuição considerável da duração da lide e a pacificação desta por meio de procedimentos informais (DA SILVA, 2009, p. 127). 
A primazia pela proximidade das partes diante do conflito é, sem dúvidas, um ponto valoroso da conciliação, considerando-se, por oportuno, que a solução adotada é, então, condizente com as realidades vividas pelos conflitantes, uma vez que emana da vontade deles. Carecendo, no entanto, da atuação de um terceiro nesse processo, o qual vai gerenciar essa negociação, a qual pode ser definida como sendo a cessão mútua das partes. Outrossim, é válido mencionar, nesse ponto, que o conciliador deve se atentar à solução por elas acordada, com o fito de que ao final logre-se uma convivência pacífica (ORSINI; DE MELLO; AMARAL, 2011, p. 46).

Esse terceiro a promover o gerenciamento do conflito, deve fazê-lo de forma neutra e imparcial. Podendo, também, além de expor propostas, sugerir um acordo a ser pactuado pelas partes, após uma análise dos prós e dos contras de cada lado, sempre com o fim de lograr a composição da lide. O conciliador, por sua vez, pode ser escolhido pelas partes, ou investido de autoridade (MENDES, 2009, 122).

A atuação como conciliador exige uma qualificação apropriada. Dessa forma, deve tal profissional ser bacharel ou estudante de Direito, de preferência. O norte a guiar a sua atuação profissional deve ser a verdadeira conciliação das partes. Este fim almejado, por ser a tentativa de se obtê-lo condição necessária para que se passe à fase de instrução e julgamento no âmbito dos juizados especiais, torna esse instrumento tão prestigiado nessa esfera. Nesta, o instituto em questão se caracteriza como instrumento processual apto a promover a efetiva solução de conflitos de forma célere. Contribuindo, portanto, com a atividade jurisdicional ao propiciar mais qualidade e rapidez a esta (MENDES, 2009, p. 122-123).

A qualificação dos conciliadores deve, igualmente, advir da adequada capacitação desses profissionais. Isso porque, essa é a maneira de assegurar que o instrumento seja devidamente realizado. Aproveitando ao máximo essa oportunidade, o que gera por consequência, maiores chances de ser o acordo cumprido. Culminando, desse modo, numa composição efetiva (SALES, 2014, p. 
262). Em que pese a linha limítrofe entre conciliação e mediação parecer, por vezes, tênue, há distinções entre os dois mecanismos, conforme tratar-se-á em seguida.

Tanto a mediação, quanto a conciliação visam promover o consenso entre as pessoas diante de certo litígio. Acontece que a conciliação tem a realização de acordos como o seu fim maior, ou até mesmo o único, em determinadas situações, ao passo que na mediação, conquanto tenha esse instituto a vocação suprema de promover o acordo, este jamais é o seu único escopo (ALMEIDA, 2015, p. 86).

Outro traço distintivo entre a mediação e a conciliação consiste em que, enquanto na última o conflito é tratado de forma superficial, na primeira o trato ao litígio é mais profundo. Isso resulta no fato de que na conciliação, o resultado muitas vezes é apenas satisfatório em partes, ao passo que na primeira a satisfação dos participantes é completa (SPENGLER, 2010, p. 37).

$\mathrm{O}$ acordo selado na esfera da mediação é de responsabilidade integral dos participantes do processo mediativo, enquanto na conciliação essa participação ativa pode ser atenuada pelo conciliador durante o processo. É essencial destacar, também, que a depender do andamento do processo conciliatório, pode o conciliador participar de forma mais ativa, caso a comunicação das partes não seja satisfatória ou inexistente. Neste último processo há, portanto, uma restrição parcial do protagonismo das partes conflitantes no firmamento do acordo (DE ALMEIDA, 2014, p. 3).

A passividade do mediador é, então, a distinção fundamental existente entre a mediação e a conciliação. Nesta, o terceiro imparcial coordena uma atividade mais dinâmica, focada sobretudo no aspecto objetivo, qual seja- a resolução do conflito. Sem haver, primordialmente, uma preocupação em recuperar a relação dos participantes, diferentemente da mediação. Na sessão de conciliação, restando frustradas as possibilidades de se chegar a um acordo, pode o conciliador ainda apontar outras opções e meios de se chegar à pacificação da contenda (DE ALMEIDA, 2014, p. 3). 
O Papel Dos Métodos Adequados De Solução De Conflitos Em Tempos De...

A conciliação no viés do Poder Judiciário nos dias atuais é muito distinta da do século anterior. Ainda há de se falar, contudo, em distinções entre esse instrumento e a mediação. Dessa maneira, podese defini-lo como um processo consensual curto, no qual as partes contam com o auxílio de um terceiro imparcial, ou por um conjunto de pessoas sem interesse na causa, os quais se valem de técnicas apropriadas com o fim de se atingir a solução do conflito. Este, por sua vez, para ser gerenciado por meio de conciliação deve ser de uma menor complexidade (AZEVEDO, 2016, p. 22-23).

Sendo assim, conciliação e mediação são meios alternativos à judicialização dos conflitos. Tais mecanismos são aptos a resolver diversos tipos de conflitos, com a marca distintiva de se voltarem para a manutenção dos relacionamentos das partes envolvidas no conflito. O terceiro facilitador, por sua vez, pode se utilizar das mais variadas abordagens, ante à existência de verdadeiras escolas de mediação. A cautela que se faz necessária, contudo, é no sentido de não haver preocupação apenas em garantir a celeridade e em sanar o abarrotamento de processos do Judiciário. Faz mister, desse modo, que tais instrumentos sejam manejados de forma a assegurar resultados exitosos, consoante os ensinamentos de Cappelletti (FERNANDES; DE PAULA, 2018, p. 16).

\section{A ATUAÇÃo DO PODER JUDICIÁRIO FRENTE ÀS RESTRIÇÕES ORIUNDAS DA PANDEMIA DA COVID-19, COM ÊNFASE NOS MÉTODOS AUTOCOMPOSITIVOS DE RESOLUÇÃO DE CONFLITOS}

Diante do panorama apresentado na secção anterior, o Poder Judiciário leva à sociedade a resolução de conflitos através da justiça multiportas. Ideia essa que visa proporcionar, para além da via 
heterocompositiva, outras formas adequadas de resolução de conflitos, com a necessidade de observância às regras impostas para a aplicação dos seus métodos.

Conforme já mencionado, normas provindas do Conselho Nacional de Justiça, com destaque à Resolução $n^{0}$ 125/2010, são responsáveis por formatar a política pública para a resolução dos conflitos, dispor acerca regulação e ampliação dos MASCs. Nessa senda, o art. 334 do CPC/2015 prevê a obrigatoriedade da realização de tentativa de conciliação na fase inicial de todas as ações cíveis. $\mathrm{Na}$ mesma maneira, o art. 695 regulamenta as ações de família (SORRENTINO; SORRENTINO, p. 19, 2020).

Destaca-se, também, que o CNJ propôs a continuidade de tais métodos, ainda que durante a pandemia, por meio da utilização de recursos tecnológicos, já que a modernização e o uso de tais recursos são diretrizes basilares do CNJ. O manejo das referidas técnicas, por sua vez, possui o escopo de aperfeiçoar o funcionamento do Judiciário.

Historicamente, com a aprovação da Emenda Constitucional (EC) $\mathrm{n}^{0}$ 45, em 2004, conhecida como a emenda da "Reforma do Judiciário", a qual se deu em 2005, houve a instalação do CNJ. Este, foi responsável por centralizar as estatísticas judiciais, por recebê-las, processá-las e publicá-las. O CNJ passou também a coletar dados e publicar anualmente o relatório Justiça em Números. Nesse norte:

\footnotetext{
A produção de dados estatísticos confiáveis, que permitam a instituição de um planejamento estratégico e o monitoramento de ações voltadas à melhoria da prestação jurisdicional, faz parte de uma tendência global na administração pública, no sentido de adotar instrumentos capazes de monitorar o desempenho organizacional e orientar práticas voltadas à otimização da alocação de recursos e à melhoria dos serviços prestados. (OLIVEIRA; CUNHA, 2020).
}

Com o avanço da pandemia no Brasil, em meados de março de 2020, o CNJ precisou articular medidas para preservação dos serventuários e usuários da Justiça contra a disseminação da COVID19, mas também que garantisse o acesso à justiça neste período emergencial. 
O cenário posto, pautado na primazia do isolamento social, vem exigindo movimentos no sentido de uma maior adoção de tecnologias com a finalidade de suprir algumas lacunas. A tramitação de processos por meio digital, regulamentada em 2006, já era realidade na maioria dos Tribunais, mesmo antes do coronavírus. $\mathrm{Na}$ Justiça Estadual, por exemplo, o índice de processos sem papel chega a 82,6\%, de acordo com o Relatório Justiça em Números 2019, do Conselho Nacional de Justiça (CNJ) (KNEVITZ, 2020).

Em razão disso, há uma destinação específica de recursos para modernização dos Tribunais em todo o país, concebendo o uso da tecnologia como um importante aliado no combate à morosidade das demandas judiciais, segundo o próprio CNJ em 2010:

(...) o CNJ instituiu um programa de apoio à modernização tecnológica dos tribunais, que já investiu mais de $\mathrm{R} \$ 100$ milhões na compra de equipamentos de informática, que já foram entregues aos diversos órgãos do Judiciário. Novos equipamentos estão sendo adquiridos para completar a primeira etapa do projeto de modernização, que prevê que todos os tribunais do país alcancem um padrão menos desigual de modernização. (BRASIL, 2010).

Graças ao uso do processo digital, as Cortes puderam manter as suas atividades funcionando durante a pandemia, o que ainda está em curso. A maioria dos Tribunais teve condições de dar prosseguimento em atos de distribuição, despachos, sentenças, decisões, acórdãos etc., ainda que fechadas fisicamente. Também é fundamental o investimento em novas formas de resolução de conflitos, de modo a prevenir a judicialização, e nisso a tecnologia também pode contribuir. Atualmente, por exemplo, há soluções que facilitam a negociação de acordos em plataformas digitais, prevenindo litígios. Isso pode contribuir na redução do congestionamento das nossas Cortes (CNJ, 2020).

Tendo como marco a pandemia do novo coronavírus, mudanças e atos normativos buscam, essencialmente, assegurar o funcionamento do Poder Judiciário, com respeito à garantia dos serviços essenciais à Justiça para população. Observando, 
simultaneamente, as recomendações das autoridades de saúde para conter a disseminação da COVID-19.

Nessa senda, o Conselho Nacional de Justiça aprovou a Resolução $n^{0}$ 313/2020, que regulamenta o regime especial do Judiciário enquanto durar a pandemia da COVID-19, ao mesmo tempo em que padroniza a atividade dos mais de 90 tribunais que funcionam em todo o país.

Tal ato normativo estabeleceu o funcionamento dos serviços judiciários, com o objetivo de prevenir o contágio pelo novo Coronavírus - COVID-19, e garantir o acesso à justiça neste período emergencial. Importante frisar que os atos normativos são- a Resolução $n^{0} 314$, de 20 de abril de 2020 , a Resolução $n^{0}$ 317, de 30 de abril de 2020, a Resolução ${ }^{0}$ 318, de 7 de maio de 2020 e a Portaria $\mathrm{n}^{0} 79$, de 22 de maio de 2020. (BRASIL, 2020). A principal ferramenta do Judiciário para continuidade da prestação jurisdicional é o uso da tecnologia. Esta pauta, como já mencionado, é priorizada e, inclusive, já está prevista em alguns diplomas legais para auxiliar os serviços da Justiça.

O próprio Código de Processo Civil de 2015 reforçou a competência do CNJ para regulamentar a incorporação gradual de recursos tecnológicos, in verbis:

Art. 196. Compete ao Conselho Nacional de Justiça e, supletivamente, aos tribunais, regulamentar a prática e a comunicação oficial de atos processuais por meio eletrônico e velar pela compatibilidade dos sistemas, disciplinando a incorporação progressiva de novos avanços tecnológicos e editando, para esse fim, os atos que forem necessários, respeitadas as normas fundamentais deste Código.

Acertadamente, trouxe o diploma processual civil outras normas prevendo a possibilidade de que sejam adotados recursos tecnológicos em determinadas situações, a exemplo do depoimento pessoal da parte, bem como a sustentação oral de advogados desde que preenchido o requisito do art. 937, $\S 4^{\circ}$ do referido diploma.

Art. 236. Os atos processuais serão cumpridos por ordem judicial. 
§ $3^{0}$ Admite-se a prática de atos processuais por meio de videoconferência ou outro recurso tecnológico de transmissão de sons e imagens em tempo real.

Art. 937, $\S 4^{\circ}$ É permitido ao advogado com domicílio profissional em cidade diversa daquela onde está sediado o tribunal realizar sustentação oral por meio de videoconferência ou outro recurso tecnológico de transmissão de sons e imagens em tempo real, desde que o requeira até o dia anterior ao da sessão.

Art. $385, \S 3^{\circ} \mathrm{O}$ depoimento pessoal da parte que residir em comarca, seção ou subseção judiciária diversa daquela onde tramita o processo poderá ser colhido por meio de videoconferência ou outro recurso tecnológico de transmissão de sons e imagens em tempo real, o que poderá ocorrer, inclusive, durante a realização da audiência de instrução e julgamento.

Nesse diapasão, fora publicada a Lei $n^{0} 13.994$, de 24 de abril de 2020, de autoria do deputado e jurista Luiz Flávio Gomes, que altera a Lei dos Juizados Especiais para possibilitar a conciliação não presencial no âmbito dos Juizados Especiais Cíveis, mediante o emprego dos recursos tecnológicos disponíveis de transmissão de sons e imagens em tempo real. Necessitando o resultado da tentativa de conciliação ser reduzido na minuta da ata de audiência. Ressalta-se a importância do mencionado diploma legal, tendo em vista que ele regulamenta a realização da audiência de conciliação virtual nos Juizados Especiais. (BRASIL, 2020).

A resolução de conflitos por meio eletrônico difere-se dos métodos tradicionais, em face de ser operacionalizada por uma plataforma online, além de trazer diversos benefícios para as partes, dentre eles: praticidade, celeridade, facilitação na comunicação, privacidade e sigilo, redução de desgaste emocional e maior possibilidade de acordo. Outro diferencial importante da mediação ou da conciliação eletrônica, está na redução dos custos financeiros (DI VASCONCELOS, 2016).

Assim, tendo em vista o hodierno cenário de imprevisibilidade, a vídeo conferência é um recurso tecnológico que permite a manutenção das audiências, por atender a finalidade constitucional do acesso ao Poder Judiciário. Igualmente, possibilita que as partes se manifestem livremente com todas as suas expressões 
expostas a serem ouvidas e vistas por meio de câmeras e microfones. (ALMEIDA; PINTO, p. 12, 2020).

Nessa senda, a Plataforma Emergencial de Videoconferência (Cisco Webex) foi o meio encontrado pelo Conselho Nacional de Justiça, com a finalidade de que a realização das audiências virtuais tivesse maior segurança e comodidade. Destarte, foi a citada plataforma disponibilizada para os tribunais, propiciando a realização de audiências e sessões de julgamento nos órgãos do Poder Judiciário, sendo instituída através da Portaria $n^{0}$ 61/2020. (BRASIL, 2020).

A plataforma retro mencionada foi disponibilizada pelo $\mathrm{CNJ}$ a todos os segmentos de Justiça, Juízos de Primeiro e Segundo Graus de jurisdição, e também para os tribunais superiores. O Termo de Cooperação Técnica $n^{0}$ o07/2020, por sua vez, é o documento que lastreia a adoção do sistema em questão. O seu uso é facultativo e não exclui a utilização de outras ferramentas que alcancem o mesmo objetivo. Um dos recursos que a plataforma possui é o compartilhamento em tempo real de áudio, vídeo e documentos. Permite, também, a gravação das audiências presenciais e à distância, além da inclusão automática no processo judicial (BRASIL, 2020).

Ademais, já vem sendo suscitada por doutrinadores a possibilidade de intimação por telefone, dadas as restrições que perpassam o país. Tal modalidade vem ganhando realce, inclusive para comunicação sobre a audiência de conciliação virtual. Para Geraldo Lopes (p. 40, 2020):

É possível afirmar que a intimação por telefone encontra amparo legal, não sendo o caso de prática ilegal, pois a previsão legal das formas de intimação não afastam essa nova hipótese, ao contrário estabelece que deve ser feita sempre que possível por meio eletrônico (art. 270, CPC), essa possibilidade é reforçada pela lei 9.099/95, que esclarece que pode ser feita por qualquer meio idôneo de comunicação, ( $\S 2^{0}$ do art. 13 , art. 19 e art. 67 da Lei 9099/95); não obstante, salutar lembrar que o momento que vivemos, é excepcional, sendo ainda mais indicado a possibilidade da utilização dos meios idôneos disponíveis, para se alcançar a justiça.

A propósito da discussão sobre a legalidade da intimação por telefone, oportuno mencionar que alguns tribunais já aderiram à 450 
referida modalidade, incluindo o Tribunal Regional da $3^{\mathrm{a}}$ Região. Este, por meio da Resolução $\mathrm{n}^{0}$ 10/2016, normatizou a utilização de procedimento para intimação por via de aplicativo WhatsApp, no trâmite de processo de competência dos Juizados Especiais Federais e Turmas Recursais. (LOPES, p. 41-42, 2020).

Com isto, verifica-se que o conjunto de normas que disciplinam a virtualização de atos, procedimentos e sessões de julgamento durante a pandemia anteciparam o prognóstico de que o funcionamento dos Tribunais seria transformado pela tecnologia e sua utilidade vem sendo reconhecida no aprimoramento do Poder Judiciário. Nesse sentido:

Diante da pandemia do Corona vírus, a ampliação da realização eletrônica da audiência preliminar torna-se imprescindível à manutenção do efetivo acesso à ordem jurídica, já que as partes que possuam acesso aos meios digitais, conhecendo minimamente as ferramentas necessárias e possuindo interesse mútuo, deverão ter à sua disposição a possibilidade de realização eletrônica da audiência inaugural. (SOUZA NETTO; FOGAÇA; GARCEL, p. 6, 2020).

A partir de tais considerações, importa ressaltar que os Tribunais de cada unidade federativa também planejam suas metas em consonância ao que é pautado pelo CNJ. Verifica-se que os objetivos do Planejamento Estratégico de Tecnologia da Informação devem se alinhar com os objetivos estratégicos no tocante ao Poder Judiciário Alagoano, por exemplo. Nessa mesma linha, almeja-se o aumento da produtividade através da capacitação técnica e de melhores condições de trabalho no sentido amplo, em busca de soluções e inovações (TJ/AL, 2010).

A meta do Tribunal de Justiça de Alagoas é avançar para além da digitalização do processo, tornando eletrônicas todas as fases e decisões, migrando-se do meio físico para o eletrônico da forma mais segura possível. Com a implantação desse sistema a vários níveis, objetiva-se que em todo país as petições, as publicações, os documentos e os andamentos processuais sejam todos digitais. (TJ/AL, 2010). 


\section{O TRIBUNAL DE JUSTIÇA DE ALAgOAS NO CONTEXTO DO USO DE RECURSOS TECNOLÓGICOS DURANTE A PANDEMIA}

Em 2010, o Tribunal de Justiça de Alagoas traçou metas para os anos de 2011 a 2015 no que diz respeito ao Planejamento Estratégico de Tecnologia da Informação no âmbito do Poder Judiciário em Alagoas - TJ/AL. A contribuição da criação deste planejamento teve duas diretrizes. Inicialmente facilitar o acesso à Justiça, promovendo a capilaridade dos sistemas e serviços, bem como na promoção da cidadania, permitindo que os sistemas e serviços estejam disponíveis a todos os cidadãos (TJAL, 2010).

$\mathrm{O}$ referido Planejamento Estratégico aderiu à tendência de automatização de processos administrativos e operacionais. Se empenhando, portanto, cada vez mais na informatização da Justiçano âmbito dos seus processos e de suas rotinas. Atualmente, o Poder Judiciário de Alagoas já conta com 100\% de suas comarcas informatizadas. Com a utilização desses sistemas computacionais, as comarcas conquistaram um aumento notável na rapidez e na qualidade de seus trâmites processuais (TJAL, 2010).

Além disso, o TJAL conta com o apoio de diversos sistemas desenvolvidos por uma equipe de analistas lotados na Diretoria Adjunta de Tecnologia da Informação, que automatizam os processos administrativos internos.

A propósito das Resoluções do CNJ e das referidas previsões do CPC/2015, o Poder Judiciário de Alagoas adotou medidas de prevenção ao novo Coronavírus, inclusive, o teletrabalho, bem como as audiências virtuais no âmbito do Núcleo Permanente de Métodos Consensuais de Resolução de Conflitos (Nupemec), Juizados Especiais e Órgãos da $2^{\mathrm{a}}$ instância, a exemplo da Resolução $\mathrm{n}^{\circ}{ }^{\mathrm{1}}$, de 26 de maio de 2020. Em sintonia, pois, com a Resolução TJ/AL no ${ }^{0}$, de 28 de março de 2017, que instituiu o de Gestão de Tecnologia da Informação 
e Comunicação do Poder Judiciário do Estado de Alagoas CGGESTIC-AL.

Vários tribunais pelo Brasil já conseguiram importantes resultados com a adoção de recursos tecnológicos, em que pese as restrições advindas da pandemia. Nesse diapasão, cabe destacar o Judiciário de Pernambuco que apresentou os seguintes dados:

\begin{abstract}
Nos meses de abril e maio, o Núcleo Permanente de Métodos Consensuais de Resolução de Conflitos (Nupemec) do Judiciário pernambucano realizou 2.153 audiências no formato on-line, com a celebração de 787 acordos e uma movimentação financeira de $\mathrm{R} \$ 13,5$ milhões. As sessões de mediação e conciliação nos Centros Judiciários de Solução de Conflitos e Cidadania (Cejuscs) da Justiça estadual vêm ocorrendo desde o início da pandemia, no mês de março, quando a Presidência do TJPE, através da Instrução Normativa $\mathrm{n}^{0} 5$, facultou às referidas unidades a utilização do aplicativo WhatsApp para a promoção da solução de conflitos (CNJ, 2020).
\end{abstract}

O Tribunal de Justiça de Alagoas, por sua vez, publicou o Ato Normativo $\mathrm{n}^{\mathrm{o}}$ 11, no dia 13 de abril de 2020, autorizando e fixando regras para a realização de audiências processuais por meio de videoconferências, durante o período de distanciamento social imposto pela pandemia de COVID-19. Enfatiza-se o trabalho desempenhado pela Centro Judicial de Solução de Conflitos (Cejusc) do Fórum da Capital que começou no dia 30 de março de 2020, a realizar audiências de conciliação por meio de vídeo chamada no WhatsApp.

Frisa-se que, além das demandas cíveis residuais, as Varas de Família de Maceió/AL remetem ao CEJUSC os processos que necessitem maior celeridade na tramitação, a fim de que seja verificada a possibilidade de realização de audiência por videoconferência.

Diante deste contexto, a partir das informações e dados fornecidos pelo Setor de Divisão de Estatísticas do Tribunal de Justiça de Alagoas - DETJ/AL, verifica-se que houve um grande número de audiências de conciliação/mediação realizadas pela modalidade virtual, conforme a tabela abaixo: 


\begin{tabular}{|c|c|c|c|c|c|c|}
\hline Unidade & Março & Abril & Maio & Junho & Julho & $\begin{array}{c}\text { Total } \\
\text { Geral }\end{array}$ \\
\hline Cartório Cjusc/Casa de Direitos & 21 & 0 & 0 & 0 & 5 & $\mathbf{2 6}$ \\
\hline Cejusc/Violência Doméstica & 2 & 0 & 0 & 1 & 2 & $\mathbf{5}$ \\
\hline $\begin{array}{c}\text { CENTRO JUDICIÁRIO DE } \\
\text { SOLUČ̃̃O DE CONFLITOS E }\end{array}$ & & & & & & \\
CIDADANIA-CJUS/PROCESSUAL & 313 & 68 & 96 & 101 & 96 & $\mathbf{6 7 4}$ \\
\hline Cjusc-Base Comunitária & 0 & 0 & 1 & 0 & 1 & $\mathbf{2}$ \\
\hline Vara Cjusc/Fórum Capital & 14 & 3 & 0 & 0 & 1 & $\mathbf{1 8}$ \\
\hline Total por mês & $\mathbf{3 5 0}$ & $\mathbf{7 1}$ & $\mathbf{9 7}$ & $\mathbf{1 0 2}$ & $\mathbf{1 0 5}$ & $\mathbf{7 2 5}$ \\
\hline
\end{tabular}

O Poder Judiciário adotou como meta o estímulo à conciliação, em decorrência disso o Tribunal de Justiça de Alagoas também propõe medidas para ampliação dos métodos autocompositivos. Nos últimos anos, houve a expansão dos setores do Centro Judiciário de Solução de Conflitos e Cidadania (Cejusc), em Maceió, a exemplo dos núcleos implementados no Juizado de Violência Doméstica, na Base Comunitária da Polícia Militar no bairro Vergel do Lago e na Casa de Direitos no bairro Jacintinho.

Contudo, as maiores demandas são encaminhadas para o Cejusc sediado no principal Fórum da Justiça Estadual, que conta com melhor estrutura e maior número de servidores/conciliadores, este Centro Judiciário encabeçou o uso de recursos tecnológicos durante a pandemia para realização das audiências.

No tocante aos dados apresentados na tabela, frisa-se que as audiências virtuais de conciliação só ocorrem com a autorização das partes do processo, visto a importância da livre motivação dos sujeitos processuais para o diálogo e resolução do litígio e desde que tenham domínio sobre a utilização da tecnologia disponível para a participação em audiências com uso de ferramentas tecnológicas.

Resta evidente, pois, que tanto a mediação, quanto a conciliação, têm o mérito de conceder às partes afetadas o poder de finalizar, em comum acordo, o conflito que as une, construindo-se uma solução que atenda aos interesses reciprocamente considerados através de uma decisão informada e consciente, oriunda da autonomia da vontade. É, sem dúvida, uma forma de diminuição dos casos que precisam ser levados à apreciação judicial, ou, ainda que 
O Papel Dos Métodos Adequados De Solução De Conflitos Em Tempos De...

imprescindível, servem como técnica de aceleração no trâmite processual, operando tratamento mais adequados aos conflitos e incentivando a participação do interessado na norma que regulará seu caso, instrumentalizando, portanto, o autorregramento (DIDIER JUNIOR, 2015, p. 280).

Levando em consideração o cenário atual de pandemia, que afetou a sociedade nas mais variadas esferas, mostra-se de vital importância a continuidade da realização das audiências de conciliação e mediação por parte do Judiciário (na modalidade online) - no caso em análise pelo Judiciário de Alagoas. Isso porque, aos cidadãos é garantido o acesso à justiça, por meio da possibilidade de pacificar os seus conflitos de maneira dialogada e consensual, mesmo que de modo virtual. Trata-se, portanto, de posição salutar e valorosa por parte do Judiciário, uma vez que é tendente a garantir efetividade ao artigo $5^{\circ}, \mathrm{XXXV}$, da Carta Magna.

Os modelos de tratamento de conflitos e de ampliação ao acesso à justiça "compõem o hoje denominado sistema multiportas, que engloba as práticas restaurativas, a facilitação de diálogos apreciativos, etc., e pode ser livremente adequado, consoante as necessidades e circunstâncias pessoais e materiais de cada situação (VASCONCELOS, 2015, p. 56)". Inclusive na adoção de práticas virtuais em que sejam respeitados os princípios norteadores dos MASCs.

Sendo assim, apresentam-se os resultados obtidos em pesquisa que objetivaram encontrar dados quantitativos referentes à aplicabilidade dos métodos consensuais na modalidade virtual. Com efeito, as mudanças estratégicas implementadas pelo Tribunal de Justiça de Alagoas (TJAL), a respeito da inclusão das vias remotas para realização de audiência, determinou o considerável o dado de que até julho de 2020 foram realizadas 674 audiências pelos servidores do Centro Judiciário de Solução de Conflitos e CidadaniaCjus/Processual, caracterizando, assim, a continuidade na prestação de serviços do Poder Judiciário em Alagoas, com o recorte da capital Maceió. 


\section{CONCLUSÃO}

Os MASCs desempenham, deveras, um papel importante na pacificação de conflitos, notadamente a mediação e a conciliação, por propiciarem o protagonismo das partes na construção dessa solução. A primeira, mais adequada em conflitos mais profundos, atrelados a relações anteriores- como nas searas de direito de família, direito do trabalho; já o segundo, mais pertinente ante conflitos menos complexos, que demandam uma solução mais rápida.

A coexistência desses instrumentos com o processo judicial tradicional mostra-se imprescindível, máxime diante da já conhecida sobrecarga do Poder Judiciário. O CNJ, acertadamente, vem há alguns anos impulsionando a articulação desses mecanismos no âmbito do Judiciário, mormente a partir da Resolução n 125/2010.

Aliado a esse processo de encorajamento dos MASCs, nota-se que, também no âmbito do Judiciário, novas tecnologias vêm sendo incorporadas à sua estrutura de funcionamento. Isso engloba, entre outros, a digitalização dos processos, a assinatura e a certificação digitais. Conquanto haja desafios em sua implementação, gradativamente novos recursos tecnológicos são agregados à Justiça. Isso tende a resultar em melhorias reais e diretas à toda a população. Tais avanços podem representar uma amenização das dificuldades encontradas na operação da justiça, máxime em face da conjuntura atual. Aprimorando, assim, não só de modo objetivo o sistema judiciário, mas também a visão da população sobre tal sistema.

A realização dos MASCs continua a se dar durante a pandemia da COVID-19 no campo do Poder Judiciário. Transladadas para o meio virtual, as sessões mediação e a conciliação estão a ocorrer na esfera da Justiça, com destaque neste trabalho à sua realização no âmbito da Justiça Alagoana.

Observou-se, por meio dos dados expostos e discutidos neste trabalho, que uma quantidade considerável de audiências de conciliação e mediação foi realizada por parte do Poder Judiciário de 
O Papel Dos Métodos Adequados De Solução De Conflitos Em Tempos De...

Alagoas, de modo virtual, de março a julho de 2020. Ante tal posicionamento, no sentido de propiciar a continuidade da realização dessas audiências no contexto de pandemia, observa-se que o acesso à justiça, na modalidade autocompositiva, foi assegurado aos cidadãos. Assim, o Poder Judiciário de Alagoas adotou posição em consonância com os contornos do acesso à justiça, no que diz respeito aos MASCs, de março- quando foi adotado o teletrabalho na esfera judicial- até o momento atual.

Assim, o Poder Judiciário de Alagoas adotou posição em consonância com os contornos do acesso à justiça, no que diz respeito aos MASCs, de março - quando foi adotado o teletrabalho na esfera judicial- até o momento atual. Destarte, demonstrou-se o número relevante de audiências virtuais realizadas pelo Centro Judiciário de Solução de Conflitos e Cidadania-Cjus/Processual, em Maceió, no intuito de seguir as recomendações do Conselho Nacional de Justiça.

Data de Submissão: 31/07/2020

Data de Aprovação: 04/10/2020

Processo de Avaliação: double blind peer review

Editor Geral: Jailton Macena de Araújo

Editor de Área: Fernando Joaquim Ferreira Maia

Assistente Editorial: Bruna Agra de Medeiros

\section{REFERÊNCIAS}

ALAGOAS. Resolução no o4, de 28 de março de 2017, do Tribunal de Justiça de Alagoas. Disponível em: https://www.tjal.jus.br/procuradoria/arquivos/fc8d8ccc2a9742cf8e b2b6687c938c48.pdf Acesso em: 28 de maio 2020.

ALAGOAS. Resolução no 18, de 26 de maio de 2020 , do Tribunal de Justiça de Alagoas. Disponível em: https://www.tjal.jus.br/procuradoria/arquivos/5de2b5ec6cf310a164 fc204da9a3oaa3.pdf Acesso em: 30 de maio de 2020. 
ALMEIDA, Marcelo Pereira de; PINTO, Adriano Moura da Fonseca.

Os impactos da pandemia de COVID 19 no Sistema de Justiça - algumas reflexões e hipóteses. Revista Juris Poiesis Rio de Janeiro. Vol. 23 - $\mathrm{n}^{\circ}$ 31, 2020, pg.01-15. Disponível em: http://periodicos.estacio.br/index.php/jurispoiesis/article/viewFile/ 8160/47966740. Acesso em 17 de jun. de 2020.

ALMEIDA, Tania. Mediação e conciliação: dois paradigmas distintos, duas práticas diversas. In Mediação de conflitos: novo paradigma de acesso à justiça. Santa Cruz do Sul: Essere nel Mondo, $2^{\text {a }}$ ed, 2015. Disponível em:

https://www.academia.edu/22380472/Media\%C3\%A7\%C3\%A30_de _conflitos_novo_paradigma_de_acesso_\%C3\%Ao_justi\%C3\%A7a. Acesso em: 24 jun. 2020.

ALVES da SILVA, Paulo Eduardo. Resolução de disputas: métodos adequados para resultados possíveis e métodos possíveis para resultados adequados. In: ALVES DA SILVA, P.E.; SALLES, C.A.; LORENCINI, M.A.G. (Org.). Negociação, mediação e arbitragem: curso de métodos adequados de solução de controvérsias. 2ed. Rio de Janeiro: Forense, 2019, v. 1, p. 13-42. Disponível em:

https://edisciplinas.usp.br/pluginfile.php/4394573/mod_resource/c ontent/1/o1-Paulo\%2oEduardo\%20Alves\%20da\%20Silva-

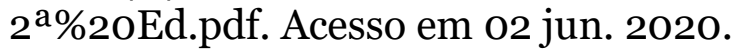

AZEVEDO, André Gomma de (org.). Manual de Mediação Judicial. 2016, 6. ed.

BRASIL. Conselho Nacional de Justiça. Agência CNJ de Notícias: Seminário discute desafios das novas tecnologias no Judiciário. Publicado em o9 de novembro de 2010. Disponível em: https://www.cnj.jus.br/seminario-discute-desafios-das-novastecnologias-no-judiciario/ Acesso em: 07 de abr. de 2020.

BRASIL. Conselho Nacional de Justiça. Agência CNJ de Notícias: Núcleo realiza mais de duas mil audiências virtuais de conciliação durante pandemia. Disponível em:

https://www.cnj.jus.br/nucleo-realiza-mais-de-duas-mil-audienciasvirtuais-de-conciliacao-durante-pandemia/ Acesso em 10 de junho de 2020.

BRASIL. Lei no 13.105, de 16 de março de 2015. Código de Processo Civil. Disponível em:

http://www.planalto.gov.br/ccivil 03/ ato2015-

2018/2015/lei/l13105.htm Acesso em: 10 de abr. 2020.

BRASIL. Lei no 13.994, de 24 de abril de 2020. Altera a Lei ${ }^{0}$ 9.099, de 26 de setembro de 1995, para possibilitar a conciliação não presencial no âmbito dos Juizados Especiais Cíveis. Disponível em: 
O Papel Dos Métodos Adequados De Solução De Conflitos Em Tempos De...

http://www.planalto.gov.br/ccivil 03/ Ato2019-

2022/2020/Lei/L13994.htm Acesso em 16 de maio de 2020.

BRASIL. Resolução no 313 de 19/03/2020 do Conselho

Nacional de Justiça. Disponível em:

https://atos.cnj.jus.br/atos/detalhar/3249. Acesso em: 20 maio 2020.

CARNEIRO, Fernanda Maria Afonso. A mediação e sua relação com a cultura de paz e pacificação social. Revista de Formas

Consensuais de Solução de Conflitos, v.5, n.2, p. 01-19, jul./dez. 2019. Disponível em:

https://indexlaw.org/index.php/revistasolucoesconflitos/article/vie w/5875/pdf. Acesso em 24 set. 2020.

DA SILVA, José Gomes. Conciliação judicial. In Videre, ano 1, n. 2, p. 123-134, jul./dez. 2009. Disponível em:

http://ojs.ufgd.edu.br/index.php/videre/article/view/695/446.

Acesso em: 27 jun. 2020.

DE ALMEIDA, Diego Assumpção Rezende. O princípio da adequação e os métodos de solução de conflitos. Doutrinas Essenciais

Arbitragem e Mediação, 2014, v. 6, p. 93-116. Disponível em: https://www.academia.edu/35175429/o_princ\%c3\%8dpio_da_adeq ua\%c3\%87\%c3\%830_e_os_m\%c3\%89todos_de_solu\%c3\%87\%c3\% 830_de_conflitos. Acesso em 22 mai. 2020.

DI VASCONCELOS, Anna Luiza. Mediação eletrônica e suas inúmeras vantagens. Notícias da Federação Catarinense de Entidades de Mediação e Arbitragem - FECEMA. Disponível em: http://www.fecema.org.br/arquivos/2248 Acesso em: 30 maio 2020

DIDIER JR., Fredie. Curso de Direito Processual Civil. Vol. 1. 17 ed. Salvador: Jus Podivm, 2015.

FERNANDES, Geovana Faza da Silveira; DE PAULA, Mônica Micaela. A judicialização das relações sociais e a adoção dos meios consensuais de solução de conflitos. Revista de Formas

Consensuais de Solução de Conflitos, v. 41, n.1, p.1-21, jan./jun. 2018. Disponível em:

https://indexlaw.org/index.php/revistasolucoesconflitos/article/vie w/3992/pdf. Acesso em: 22 set. 2020.

KNEVITZ, Reginaldo Luís Souza. Conciliação virtual: princípios e procedimentos para sessões via whatsapp em processos no Poder Judiciário de Santa Catarina. Repositório institucional da Universidade do Sul de Santa Catarina. Disponível em: https://riuni.unisul.br/handle/12345/9535?locale-attribute=pt BR Acesso em: 30 maio. 2020. 
LOPES, Geraldo Evangelista. Intimação por telefone e WhatsApp.

Tecnologia a serviço da celeridade processual - uso de mídias sociais.

Revista do Curso de Direito Centro Universitário Braz

Cubas, V4 N1: junho de 2020. Disponível em:

https://revistas.brazcubas.br/index.php/revdubc/article/view/901

Acesso em: 02 de jul. 2020.

MAZZEI, Rodrigo; CHAGAS, B. S. R. Métodos ou tratamento adequados dos conflitos? Revista Jurídica da Escola Superior de Advocacia da OAB-PR, v. 1, p. 323-350, 2018.

MENDES, Anderson de Moraes. A hora e a vez da conciliação. In Revista CEJ, n. 46, jul/set. 2009, p.120-123. Disponível em: https://www2.cjf.jus.br/ojs2/index.php/revcej/article/viewFile/129 o/1289. Acesso em: 23 jun. 2020.

SOUZA NETTO; José Laurindo De; FOGAÇA, Anderson Ricardo; GARCEL, Adriane. Métodos autocompositivos e as novas tecnologias em tempos de Covid-19: online dispute resolution odr. Revista Relações Internacionais do Mundo Atual. Volume. 1, n. 26 (2020). Disponível em:

http://revista.unicuritiba.edu.br/index.php/RIMA/article/view/398 9 Acesso em: 12 jul. 2020.

ORSINI, A. G. de S.; DE MELLO, A. F. C. V.; AMARAL, T. P. A conciliação como concretização do acesso à justiça. In Revista do Tribunal Regional do Trabalho da $3^{\mathbf{a}}$ Região: Belo Horizonte, v. 53, n. 83, p. 41-55, jan./jun. 2011. Disponível em: http://as1.trt3.jus.br/bd-trt3/handle/11103/26996. Acesso em: 26 jun. de 2020.

SALES, Lília Maia de Morais. A Mediação de Conflitos e o Direito: Desenvolvendo Habilidades e Essa Nova Realidade.Prim@ Facie, 2017, v. 16, n. 33, p. 211-p. 239. Disponível em:

https://doi.org/10.22478/ufpb.1678-2593.2017v16n33.37058.

Acesso em: 20 set. 2020.

SALES, Lília Maia de Morais. A mediação de conflitos- lidando positivamente com as emoções para gerir conflitos. Pensar, 2016, v. 21, n. 3 p. 965-986, set./dez. Disponível em:

https://periodicos.unifor.br/rpen/article/view/5289. Acesso em: 11 jun. 2020.

SALES, Lília Maia de Morais. Mediação e conciliação judicial- a importância da capacitação e de seus desafios. Sequência:

Florianópolis, n. 69, p. 255-280, dez. 2014. Disponível em: https://periodicos.ufsc.br/index.php/sequencia/article/view/21777055.2014V35n69p255. Acesso em:15 jun. 2020. 
O Papel Dos Métodos Adequados De Solução De Conflitos Em Tempos De...

SIQUEIRA, Dirceu Pereira; PAIVA, Caroline Zanetti. A utilização da mediação como forma de efetivação ao acesso à justiça e o princípio da dignidade da pessoa humana. Revista Eletrônica do Curso de Direito da UFSM, 2016, v. 11, n. 1. Disponível em:

https://periodicos.ufsm.br/revistadireito/article/view/20505/pdf. Acesso em: 12 jun. 2020.

SORRENTINO, Thiago; SORRENTINO, Luciana. Conciliação e mediação como instrumentos de suporte no combate à pandemia. Portal 61 Brasília. Disponível em: https://61brasilia.com/2020/04/13/conciliacao-e-mediacao-comoinstrumentos-de-suporte-no-combate-a-pandemia/ Acesso em: 12 de jun. 2020.

SPENGLER, Fabiana Marion. Mediação: um retrospecto histórico, conceitual e teórico. Mediação enquanto política pública: a teoria, a prática e o projeto de lei. Fabiana Marion Spengler, Theobaldo Spengler Neto (org.). 1 ed. Santa Cruz do Sul: Edunisc, 2010. Disponível em:

https://repositorio.unisc.br/jspui/bitstream/11624/1838/1/Media\% C3\%A7\%C3\%A3o\%20enquanto\%20pol\%C3\%ADtica\%2op\%C3\%BAb lica.pdf. Acesso em: 22 jun. 2020.

SUTER, José Ricardo; CACHAPUZ, Rozane Da Rosa. Mediação e conciliação como meios de resolução de conflitos e acesso à justiça. In V Encontro Internacional Do Conpedi, Montevidéu Uruguai. Anais. Florianópolis: Conpedi, 2016, p. 58-75. Disponível em:

http://conpedi.danilolr.info/publicacoes/910506b2/6jq67a8y/TzWt 600OYV30917l.pdf. Acesso em: 22 jun. 2020.

TOFFOLI, José Antônio Dias. Acesso à Justiça na Constituição de 1988 e métodos adequados de resolução de conflitos no Brasil. A vida dos direitos nos 30 anos da Constituição Federal. São Paulo: Escola Paulista da Magistratura, 2019, p. 13-33. Disponível em:

http://www.mpsp.mp.br/portal/page/portal/Escola_Superior/Biblio teca/Biblioteca_Virtual/Livros_Digitais/o03818.pdf\#page=13. Acesso em: 22 jun. 2020.

VASCONCELOS, Carlos Eduardo de. Mediação de conflitos e práticas restaurativas. 4. ed. São Paulo: Método, 2015.

ZAPPAROLLI, Célia Regina; KRÄHENBÜHL, Mônica Coelho. Negociação, Mediação, Conciliação, Facilitação Assistida, Prevenção, Gestão De Crises Nos Sistemas E Suas Técnicas.

São Paulo: LTR, 2012. Disponível em:

http://www.ltr.com.br/loja/folheie/4661.pdf. Acesso em: 12 jun. 2020 . 


\title{
The Role Of The Appropriate Conflict Resolution Methods In Covid-19 Pandemic Times In The Framework Of Alagoas Judiciary
}

\author{
Adrualdo de Lima Catão
}

Carlos David Franca Santos

Mylla Gabriely Araújo Bispo

\begin{abstract}
Alternative Disput Resolutions (ADR) are characterized by pacifying disputes, without resorting to the traditional process. Thus, playing a vitally important role within the Judiciary. Faced with the COVID-19 pandemic, the Conselho Nacional de Justiça, through Resolution 313/2020, regulated the functioning of the Judiciary through teleworking, applying this rule also to mediation and conciliation hearings. In this sense, the present study aims to analyze whether the Judiciary of Alagoas, in Maceió, adopted implemented this resolution in line with the contours of access to justice, from the beginning of the pandemic until the month of July 2020, regarding MASCs. To this purpose, bibliographic research was used and also empirical research. The latter by mapping the number of mediation and conciliation hearings held in the sphere of the Judiciary of Alagoas, in Maceió, from March to July 2020. Quantitative analysis was used, using statistics descriptive, in absolute frequency mode. The results show that the position of the Judiciary of Alagoas, in Maceió, was in accordance with the contours of access to justice, according to the parameters above, considering the expressive number of self-composed hearings in the mentioned period.
\end{abstract}

Keywords: Adequate conflict resolution methods. Pandemic. Judicial power. Technologies. Alagoas Judiciary.

DOI: https://doi.org/10.22478/ufpb.1678-2593.2020v19n42.54298

Conteúdo sob licença Creative Commons: Attribuition-NonCommercial-NoDerivative 4.0 International (CC BY-NC-ND 4.0) 